\title{
Full Scale Fatigue Test and Failure Analysis of Advanced Jet Trainer Wing
}

\author{
Vaclav Horak ${ }^{1, *}$, David Novotny ${ }^{1}$ \\ ${ }^{1}$ VZLU - Czech Aerospace Research Centre, Strength of Structures Department, Beranovych 130, \\ Prague 9, 199 05, Czech Republic
}

\begin{abstract}
A verification method for the fatigue life of the jet trainer wing with integrated fuel tanks is presented. The test was performed to identify the critical points of the structure, to determine strain data and to proof fatigue life of the wing. During the test the non-destructive inspection methods for the identification and evaluation of the critical failures were employed; i.e. visual, ultrasonic and eddy current method. The failures were classified according to significance and reparability. The special test rig was designed to redistribute the load on the structure and to determine test data. The load control system MTS AeroST ${ }^{\mathrm{TM}}$ was used for fatigue test control. The fatigue load sequences with multilevel profiles of static and fatigue loading were applied. During the test, more than 230 failures were identified. The critical failures were repaired when found using two types of repair (metal and composite). The repairs were monitored during subsequent fatigue test run and evaluated to utilize in service.
\end{abstract}

\section{Introduction}

In spite of undisputed progress and devolvement of simulation methods, the proof of aircraft structure resistance against fatigue damages is firmly based on experiments for both civil and military aircraft. The operational reliability and safety of aircraft structure must be guaranteed during the entire designed life [1]. The fatigue test of airframe or its components is the best examination of its fatigue strength and therefore also the airworthiness authorities prefers the experimental verification of service life [2]. The verification of service life should be typically conducted according to a design philosophy and the experimental verification is an integral part of the whole process [3 - 4].

The modified wing of the advanced jet trainer (AJT) was tested for fatigue life evaluation at VZLU, Strength of structures department. The fuel tanks are integrally built in the construction contrary to the older wing.

The test was performed to identify the critical points of the structure, to determine strain data and to proof fatigue life of the wing. The non-destructive inspection methods to determine the failures were employed as well. The critical failures were evaluated from the point of significance and prospective reparability.

\footnotetext{
*Corresponding author: horak@vzlu.cz
} 


\section{Fatigue test of the wing}

The wing as primary part of the aircraft structure was tested in connection to the airframe in the quasi floating layout. The fuselage was used as a wing fixture. The set-up of the test was designed to ensure the force and moment equilibria. The fatigue test was realized by loading programmed blocks with load sequences based on randomized operational load spectrum [5]. The loading blocks represented the real loads occurred during specific flight manoeuvres with or without aircraft ordnance. The specific single load events are also simulated; e.g. cannon recoil or landing impact.

\subsection{The test article}

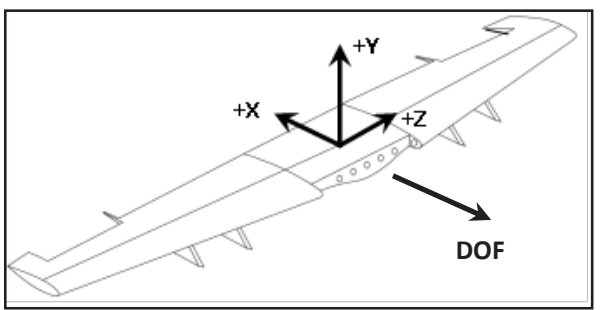

Fig. 1. Scheme of the wing with the coordinate system.

The through-wing with the integral fuel tanks was tested. The flaps, ailerons, tip tanks and control rods were dismounted (see Fig. 1). The wingspan of the wing was $9.5 \mathrm{~m}$, the maximum chord length $2.7 \mathrm{~m}$ and maximum chord height $0.35 \mathrm{~m}$.

\subsection{Load control system}

The MTS AeroST ${ }^{\text {TM }}$ load control system was used for fatigue test. It is a multichannel digital electro-hydraulic load system, which is designed for testing of aerospace structures. The load forces were generated by hydraulic actuators, equipped by load cells with force feedback and sensors of piston rod position. The load control system is equipped by advanced architecture processor which is designed to meet the wide range requirements for testing of aircraft structures (see the Fig. 2). The safety of tested structure is guaranteed by safety system working at several levels. In the case of danger situation, e.g. reaching limit deflection, sudden change of rigidity, etc., the safety system stops the test and unload the tested structure. The forces, piston rod positions, regulation differences or errors are monitored. If the signals from sensors exceed set limits the safety function acts and the corresponding state is signalized and stored [6].

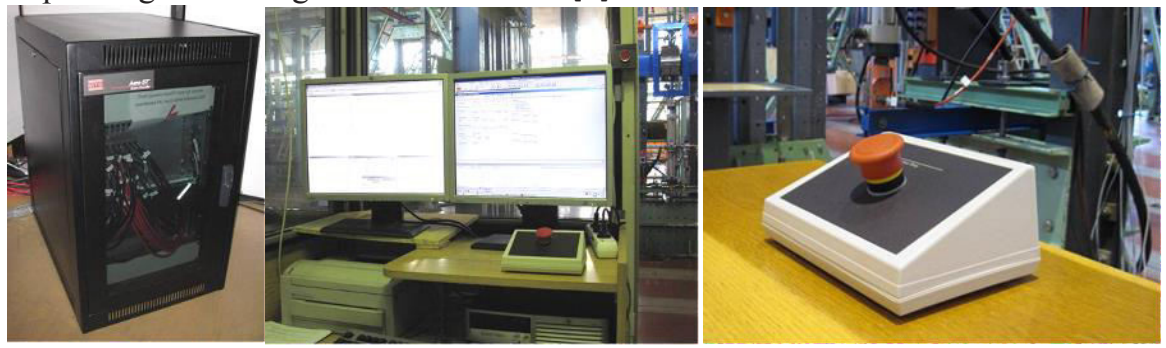

Fig. 2. a) AeroST ${ }^{\mathrm{TM}}$ load control system b) operator's workstation c) emergency button. 


\subsection{Test configuration}

The wing was fixed to the fuselage, so that the fuselage structure was not evaluated, but represented the test jig to authentically apply the load. The whole assembly of the test was fixed to the floor grid of the laboratory through load actuators equipped with the load cells The fuselage was supported in the position of selected bulkheads and the hinge of the elevator. The vertical load actuators were applied on the dummies of landing gears and on appropriate sections of the wing using load contour board clamps. The load system of the wing is shown in Fig. 3. Other load actuators in fore and aft direction were connected instead of landing gears and in weapon suspension points. The equilibrium position of the aircraft was provided by reaction rods with the load cells in appropriate points. The pressurizing of integral fuel tanks was simulated as well. The masses of all test equipment connected to the wing were balanced and their masses were compensated by counterweights; i.e. contour board clamps, dummies, load actuators, etc. The masses of moving parts and others were compensated by additional loads if appropriate [6].

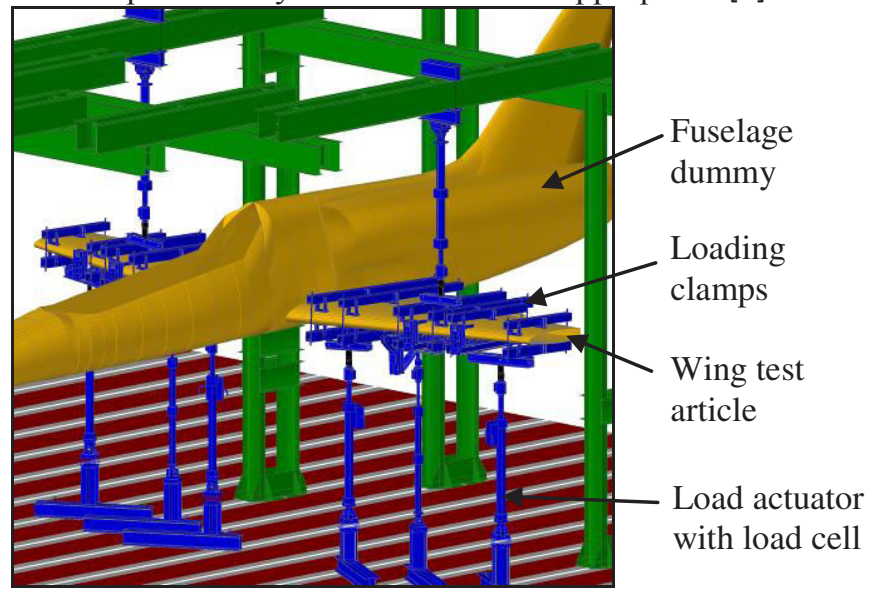

Fig. 3 The load system of the wing excluding landing gear and cannon dummy load systems.

The test rig for AJT fatigue test was assembled from the modular system available in the test laboratory (see Fig. 4). The aircraft load was transferred into the reinforced floor fixing grid. The whole assembly of the test rig (see Fig. 5) was complemented by the system for fuel filling and pressurizing of the integral tank.

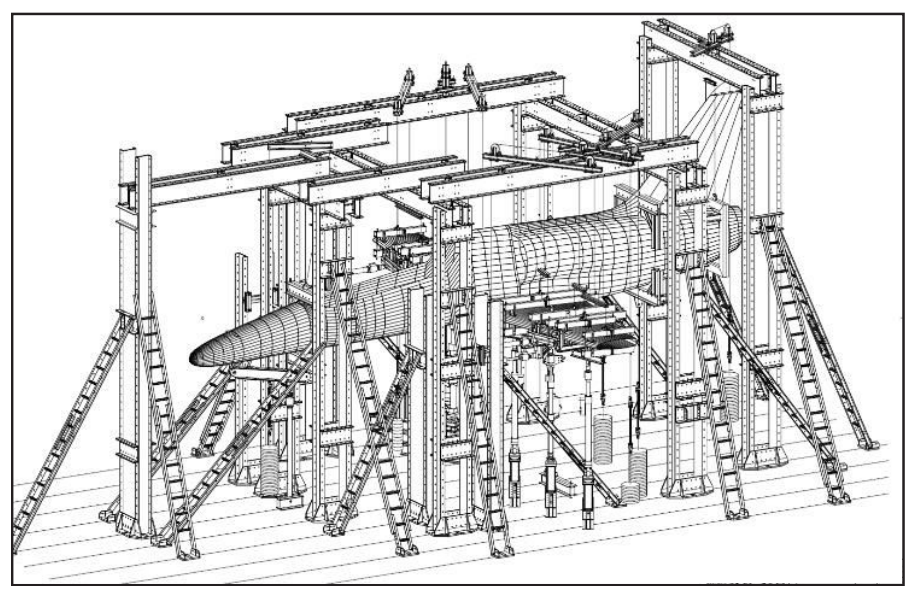

Fig. 4 The test rig with test article, load and balancing systems 


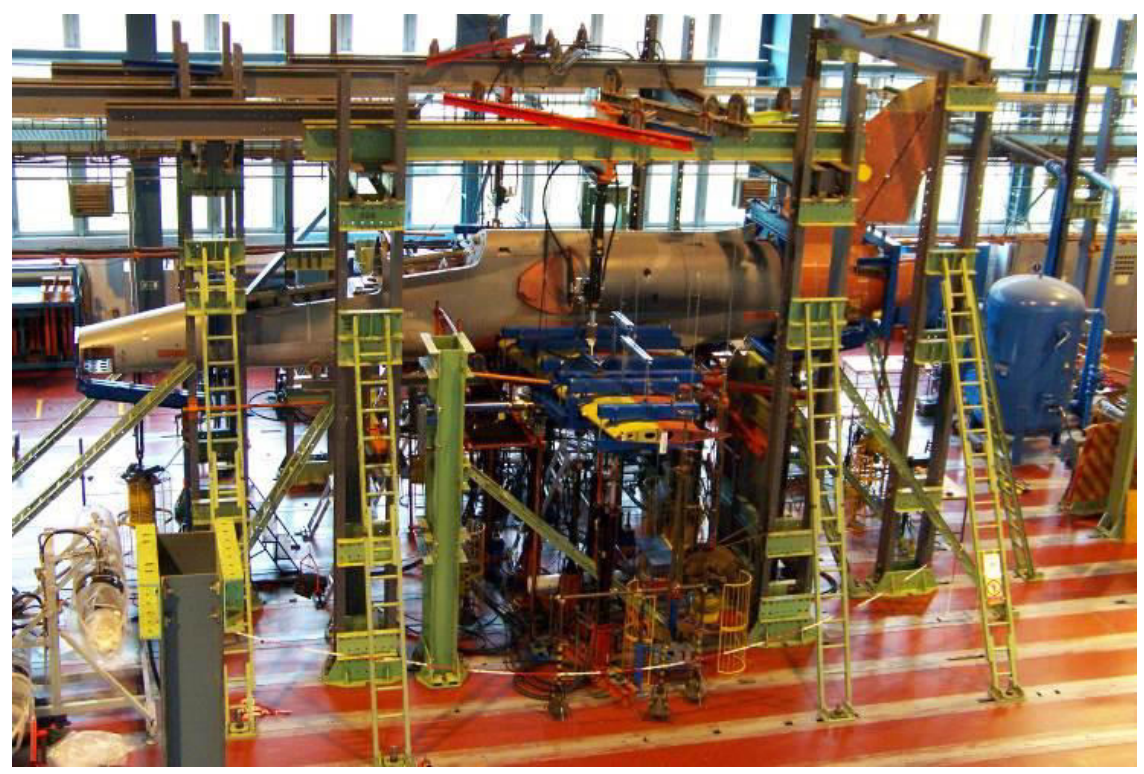

Fig. 5 The real view on the test rig for the wing fatigue test

\subsection{Measurement and data acquisition system}

During the fatigue test the static and dynamic measurements were provided. The measurement system consisted of two parts:

a) Strain gauges measurement system - static measurement for block load cases and dynamic measurement during the test article cycling in continuous loop

b) Displacement measurement system using optical incremental sensors (static measurement only)

Both acquisition systems were assembled from independent modules. The measurements were performed for special static load cases to identify and monitor the critical points of the structure and to verify the stress and strain analyses [6].

\section{Course of fatigue test and NDT inspections}

The goal of the fatigue test was to perform cyclic loading representing simulated flying hours (SFH) using cycle sequence based on the real operational conditions [7]. The static strain gauge measurements were performed in regular interval of $\mathrm{SFH}$, the dynamic measurement was provided continuously.

The non-destructive inspections (NDI) of test article and the whole airframe were performed in accordance with the test plan and technical specification as one of the most important part of the fatigue test. After the initial NDI at the beginning of the test, when an initial status of expected critical points from previous tests and service was obtained, the NDI were performed in regular interval of SFH. The inspections were performed by visual methods, in case of necessity the borescopes and/or video scope were used as well as ultra sound or eddy current methods [8]. 


\section{Analysis of the failures}

The planed service life of a metal aircraft structure subjected to cyclic loading often depends on the crack propagation during a full-scale fatigue test. Thus, to predict the service life of many structures and to establish safe inspection intervals, experimental determination of the rate of fatigue crack propagation in metal structure is required [9]. As well, an understanding to crack location specifics in order to define the optimal method of repair is required. Accordingly, a fatigue test were performed to determine the fatigue crack growth rates in structural elements of the wing with integral fuel tank and to determine the behaviour of corresponding repairs [10].

\subsection{Classification of the failures}

For the fatigue test evaluation purposes, the detected failures were classified into the categories according to their significance and reparability. The failures were initially sorted as the major and the minor failure. The major ones were present on load-carrying structural parts or caused a leak from integral fuel tank. The major failures required repair. The minor failures were present on other locations; they were small and were only monitored.

The major failures were thereafter classified into four subcategories:

1. Reparable by simple replacement of damaged part

2. Reparable by replacement of damaged part and reinforced

3. Reparable by reinforcement only

4. Non-reparable

Each of these subcategories were then divided into two classes - the reparable failures on the spot under the field conditions and the reparable failures in manufacturer's workshop only.

During the fatigue test progress, two new sub-classes have been amended: the successfully repaired failures and the unsatisfactory repaired failures. The review of all failure categories is shown in Fig. 6.

There were several detected failures on the AJT wing test article in the number of tens. Approximately half of them were the major failures. Nevertheless, several of the major failures was not able to repaire due to presence of the critical non-reparable damage.

\subsection{Major failures reparable by replacement of the damaged part}

The major failures reparable by replacement of the damaged part without reinforcing occurred as broken pin, ruptured hinge, etc. Another example is the curved L-profile stiffener of the wing skin, shown in Fig. 7. The stiffener was replaced due to its rupture by cracks in the first half of the second life. The new stiffener remained undamaged till the end of the test (4 lives), but other cracks originated on the wing skin in its neighbourhood, see Fig. 8

\subsection{Major failures reparable by the replacement of the damaged part and by the reinforcement}

The major failure reparable by replacement of the damaged part together with reinforcement is the most widely used repair method. The replaced part, the same as the original one, is not logically able to withstand the fatigue loads by itself and has to be reinforced by some stiffener [11]. During the AJT fatigue test, many failures were repaired 
in such manner; an example is shown in Fig. 9. The similar L profile stiffener was replaced and reinforced on the right side of the same part before the half of the fatigue test.

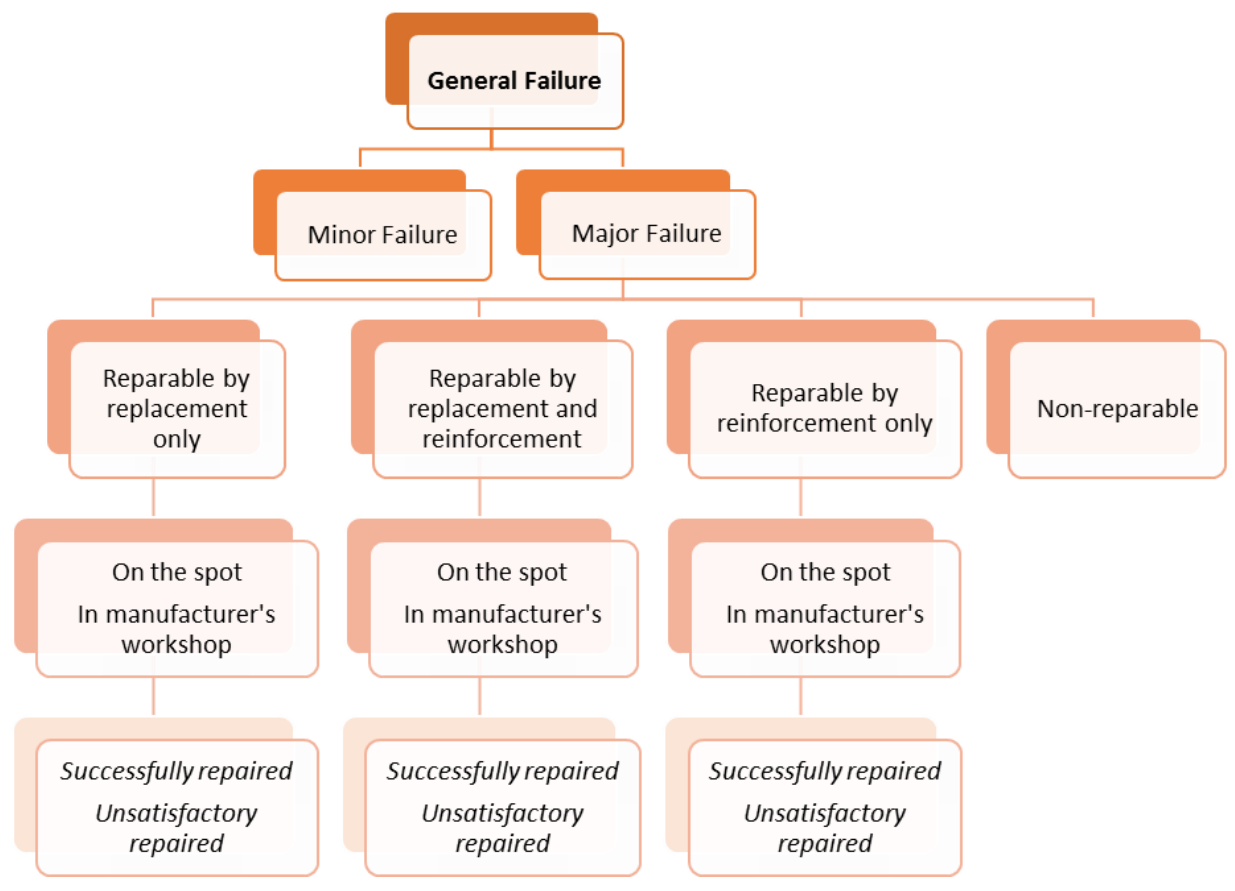

Fig. 6 Failure classification

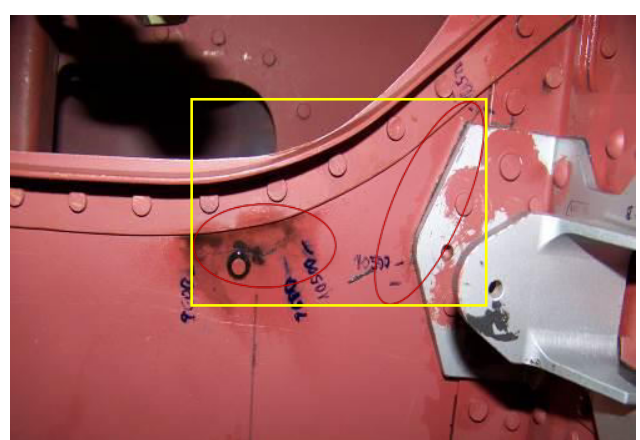

Fig. 7 Crack in L-profile stiffener

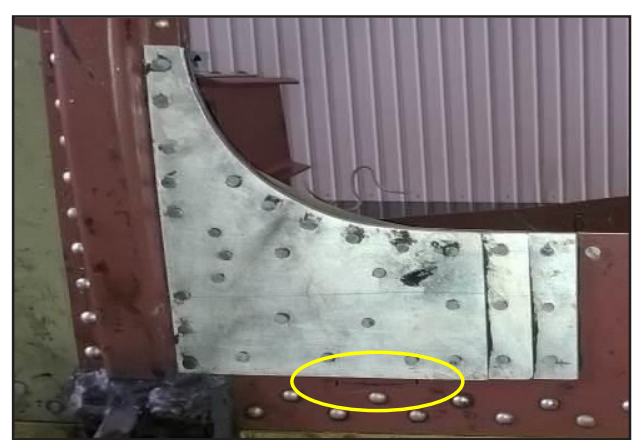

Fig. 8 Failures near the replaced stiffener 


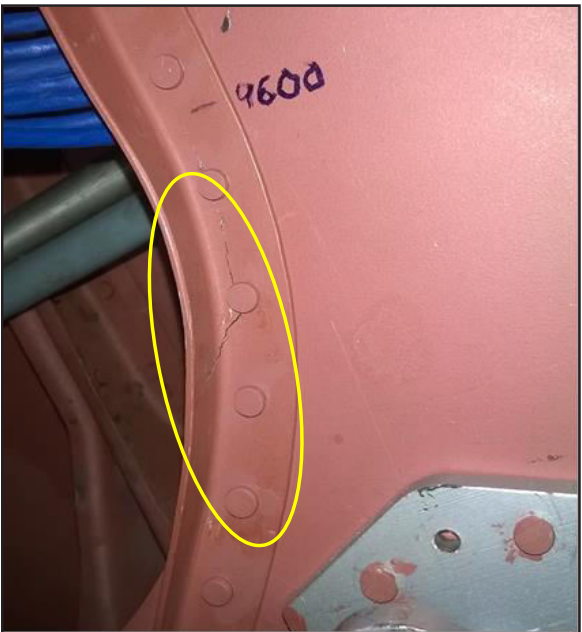

Fig. 9 Cracks near the stiffener to replace

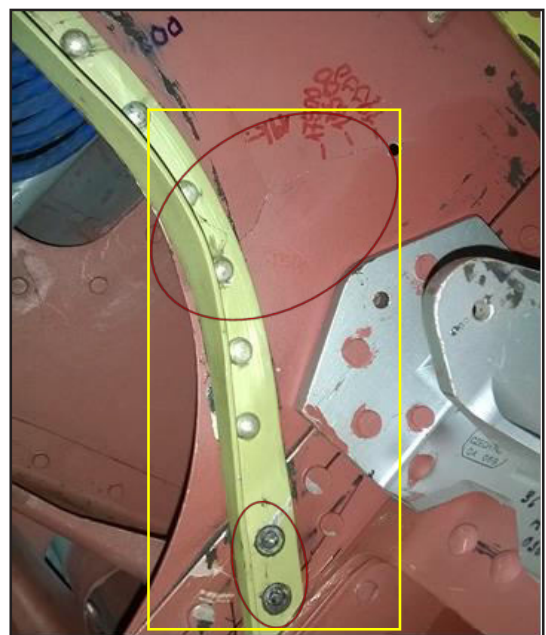

Fig. 10 Crack near the reinforcement plates

Nevertheless, some new cracks occurred in surroundings after the repair, but mostly outside the reinforcement, see Fig. 10.

Another example of the major failure repaired by replacement and reinforcement is breakage of the hinge console; see Fig. 11, which occurred at the half of the fatigue test. The repair was partly successful (see Fig. 12); some minor repairs of the rivets connecting the stiffeners to the console and replacement of the stiffeners themselves were necessary.

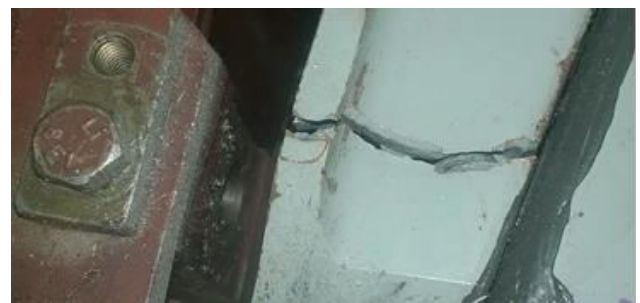

Fig. 11 Failure of hinge console

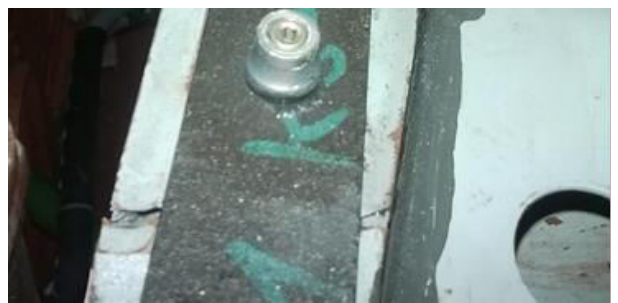

Fig. 12 Repair of hinge console

\subsection{Major failures reparable by bonded patches}

The major failure reparable by using some stiffener only was typically located on the wing skin, where replacement is impossible; see an example in Fig. 13.

The failure was repaired using adhesively bonded fibre-composite patches, see Fig. 14, that are generally more structurally efficient and much less damaging the parent structure than standard repairs based on mechanically fastened metallic patches [12]. A boron fibre composite has been used due to similar modulus of extension to aluminium alloy. This repair successfully stopped the propagation of the cracks.

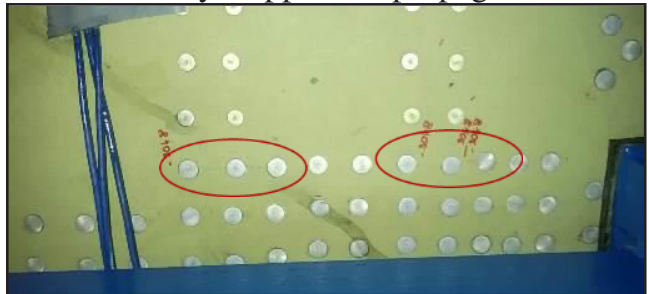

Fig. 13 Cracks on wing skin to be repaired

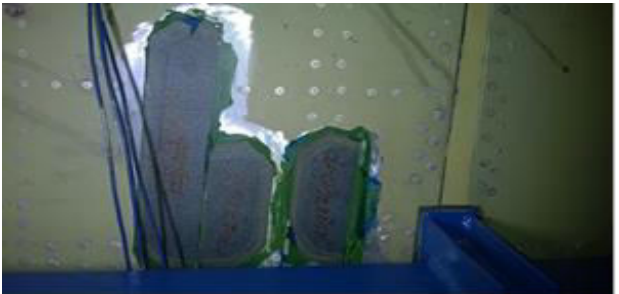

Fig. 14 Repair by composite patches 


\section{Conclusions}

By application of sequences representing the typical service condition the test article passed of about 4 service lives. Since the integrity of the aircraft structure is dependent upon the safe and controlled growth of the cracks, regular NDI inspections and crack growth monitoring are necessary to ensure the failures are detected and repaired before reaching the critical size. Therefore, the NDI of the critical points and the other areas where the damages were expected using the visual, ultrasonic and eddy current methods were performed regularly during the tests.

Different types of failure repairs and their classification have been discussed in the text, some examples have been shown. Using an appropriate method of failure inspection, correct categorization of structural failures and following monitoring of their eventual growth, even if being repaired, is a key factor for finding out of critical structural points, corresponding repair method selection and particular design modification.

The critical failures were immediately repaired during the test. The verification of these repairs was performed by subsequent test run. It was possible to evaluate the failures from the point of view of repairability. Some failures were classified as reparable and some requires the reconstruction of the critical part or the replacement by new element.

Two types of repairs (metal and composite) were tested simultaneously, the composite one showed the ability to fully substitute the well-tried metal stiffeners.

The above mentioned activities effectively decrease the outage time and the overall costs of the aircraft service due to providing with valid data to support the repair design, following repair performance and final reporting for certification purposes. The results of this test and failure analysis (tear-down, fractography, etc.) also significantly contribute to extension of service life, reduction service and maintenance cost, extension of time to repair and shortening time of the repair.

This work was supported by the Technology Agency of the Czech Republic; in frame of project TH02010670 The development of airframe for L-39NG jet trainer of new generation.

\section{References}

1. U. G. Goranson, Fatigue issues in aircraft maintenance and repairs (Elsevier Science Ltd., 1998)

2. MIL-STD 1530 A, Aircraft Structural Integrity Program Airplane Requirement

3. V. Horak, Method of certification strength test (VZLU Report R-4424,2008)

4. MIL-A-8866 B Airplane Strength and Rigidity, Reliability Requirements, Repeated Loads and Fatigue

5. F. Federer, Technical specification for fatigue test of AJT wing with integral fuel tank (AVA report L159-72601.01, Prague Vodochody 2013)

6. D. Novotny, Methodology of fatigue and static test of wing with integral fuel tank of AJT aircraft (VZLU Report R-6223-V3; Prague Letnany 2016)

7. J. Schijve, The Significance of Flight Simulation Fatigue Tests (Report LR-466, Delft University of Technology, 1985)

8. D. Novotny, Fatigue test of wing with integral fuel tank of AJT aircraft (VZLU Report R-6749 Prague Letnany 2017)

9. J. Hubr, Advanced wing AJT - failures during fatigue test( Report AVA AJT32601.04; Prague Vodochody 2016) 
10. R.B. Heywood, Design Against Fatigue (New York Pergamon Press 1969)

11. V. Kahanek, Fatigue life of aircraft structures (ALFA, Bratislava 1977)

12. F. Richi, F. Franco, N. Montefusco, Bonded Composite Patch Repairs on Cracked Aluminum Plates: Theory, Modeling and Experiments (Advances in Composite Materials - Ecodesign and Analysis, 2011) 